\title{
2 Recurrence quantification analysis of heart rate variability is 3 a COVID-safe alternative to gas analysis in the detection of metabolic thresholds.
}

G. Zimatore ${ }^{1,2}$, L. Falcioni ${ }^{3}$, M.C. Gallotta ${ }^{4}$, V. Bonavolontà ${ }^{5}$, M. Campanella ${ }^{1}$, M. De Spirito $^{6}$, L. Guidetti $^{7}$, C.Baldari ${ }^{1}$

(1) Department of Theoretical and Applied Sciences, eCampus University, Novedrate (CO), 22060, Italy,

(2) IMM-CNR, Bologna, Italy

(3) Department of Movement, Human and Health Sciences, University of Rome "Foro Italico", Rome, Italy

(4) Department of Physiology and Pharmacology "Vittorio Erspamer", Sapienza University of Rome, Italy

(5) Department of Basic Medical Sciences, Neuroscience and Sense Organs, University "Aldo Moro", Bari, Italy Department of Movement, Human and Health Sciences, University of Rome Foro Italico, Rome, Italy

(6) Fondazione Policlinico Universitario A. Gemelli IRCCS, Università Cattolica del Sacro Cuore Rome, 00168, Italy

(7) Niccolò Cusano University, Rome, Italy

Key words: phase transition, RQA, aerobic threshold, anaerobic threshold, exercise prescription, determinism, non-linear method 


\section{Abstract}

The first aim of the study was to verify if in individuals with different physical fitness levels the Recurrence Quantification Analysis (RQA) of Heart Rate Variability (HRV) time series could be an alternative to Gas Exchange (GE) analysis in the determination of metabolic thresholds. The second aim was to investigate the validity of the RQA method compared to the GE method in thresholds detection. The two metabolic thresholds were estimated in thirty young individuals during Cardiopulmonary Exercise Testing on a cycle-ergometer and $\mathrm{HR}, \mathrm{VO}_{2}$ and Workload were measured by the two different methods (RQA and GE methods). RM ANOVA was used to assess main effects of methods and methods-by-groups interaction effects for $\mathrm{HR}, \mathrm{VO}_{2}$ and Workload at the aerobic (AerT) and the anaerobic (AnT) thresholds. Validity of the RQA at both thresholds was assessed for $\mathrm{HR}, \mathrm{VO}_{2}$ and Workload by Ordinary Least Products (OLP) regression analysis, Typical Percentage Errors (TE), Intraclass Correlation Coefficients (ICC) and the Bland Altman plots. No methods-bygroups interaction effects were detected for $\mathrm{HR}, \mathrm{VO}_{2}$ and Workload at the AerT and the AnT. The OLP regression analysis showed that at both thresholds RQA and GE methods had very strong correlations $(r>0.8)$ in all variables $\left(\mathrm{HR}, \mathrm{VO}_{2}\right.$ and Workload). Slope and intercept values always included the 1 and the 0 , respectively. At the AerT the TE ranged from $4.02 \%$ to $10.47 \%$ (HR and Workload, respectively) and in all variables ICC values were excellent $(\geq 0.85)$. At the AnT the TE ranged from $2.61 \%$ to $6.64 \%$ (HR and Workload, respectively) and in all variables ICC values were excellent $(\geq 0.89)$. Our results suggest that the RQA of HRV time series is a COVID-safe approach for the determination of metabolic thresholds in individuals with different physical fitness levels, therefore, it can be used as a valid method for threshold detection alternative to gas analysis. 


\section{Introduction}

61 Due to the present COVID-19 pandemic, it is currently extremely difficult to perform safely the uptake $\left(\mathrm{VO}_{2}\right)$, carbon dioxide production $\left(\mathrm{VCO}_{2}\right)$, and ventilatory measures during an exercise test. In particular, in order to move continuously the flux air from the subject to the device, the modality of gas sampling involves the use of a face mask or a mouthpiece [1]. Therefore, given the difficulty of providing a safe and hygienic environment during every test, subjects and operators may not be appropriately protected from the risk of infection. Thus, it is necessary to develop an additional method as an alternative to Gas Exchange (GE) analysis in order to determine metabolic thresholds during an incremental exercise test. In a previous paper we proposed a new non-linear method based on Recurrence Quantification Analysis (RQA) of Heart Rate Variability (HRV) time series to estimate the aerobic threshold (AerT) in obese subjects [2]. In this special population, the AerT represents a useful parameter to identify the most appropriate physical exercise intensity in order to reduce body weight and to improve physical fitness [3]. An additional metabolic parameter frequently used during exercise testing is the anaerobic threshold (AnT). In fact, after the AerT the body leads to a greater production of lactate with the consecutive rise in ventilation in order to compensate metabolic acidosis. This is considered as an aerobic-anaerobic metabolism phase which ends with a fitness such as obese individuals. This population cannot perform an incremental physical exercise for long enough and consequently usually the AerT is the only metabolic parameter that can be determined [6]. On the contrary, the AerT and AnT can be more easily observed in a healthy population with a higher fitness level as athletes. Therefore, this population should be considered for 
Previous studies in athletes proposed several methods to provide information about the relationship between heart rate and the AerT and AnT [7-12]. However, a method based on RQA of HRV time series to distinguish the two metabolic thresholds still needs to be established. Nowadays it is extremely easy to monitor the heart rate using low-cost, non-invasive, and mobile systems [13]. The use of these devices does not necessarily require the presence of the subject in the laboratory, thus, from a practical point of view, the RQA of HRV time series could be an extremely useful method for assessing sport performance and for planning training intensity in athletes in situations where gas analysis is not permitted.

The purpose of the study was to verify if the RQA of HRV time series proposed for obese individuals can be applied also to healthy young subjects. In particular, the first aim was to assess if in individuals with different physical fitness levels the new non-linear method based on RQA could be an alternative to gas analysis in the determination of metabolic thresholds. The second aim of the study was to investigate the validity of the RQA method compared to the GE method in thresholds detection.

\section{Materials and methods}

In this paper the two evaluation methods were called Gas Exchange method (GE) and Recurrence Quantification Analysis method (RQA). In addition, the two thresholds, Aerobic (AerT) and Anaerobic (AnT), were called Aerobic Gas Exchange Threshold (AerT $\mathrm{GE}_{\mathrm{GE}}$, Anaerobic Gas Exchange Threshold (AnT $\mathrm{GE}_{\mathrm{GE}}$, Aerobic Recurrence Quantification Analysis Threshold (AerT $\mathrm{RQA}_{\mathrm{A}}$ ), and Anaerobic Recurrence Quantification Analysis Threshold ( $\left.\mathrm{AnT}_{\mathrm{RQA}}\right)$.

\section{Participants}

Thirty subjects ( 2 females; 28 males) (age $=15.7 \pm 2.7$ years) were recruited for this study. Participants were divided in three groups: competitive rowers (group A, $n=8$ ), recreational rowers 
108 (group $\mathrm{B}, \mathrm{n}=8$ ) and other recreational sports (group $\mathrm{C}, \mathrm{n}=14$ ). The A group was made up of 109 competitive rowers, i.e. athletes who performed a minimum of 5 workouts per week and have 110 participated in a regional and/or national competitions in the previous year. The subjects of group B

111 attended rowing activities twice a week. Both the A and B groups were recruited from the Circolo 112 Canottieri Tirrenia Todaro of Rome. The $\mathrm{C}$ group was made up of subjects who practice recreational 113 activities different to rowing (twice a week).

114 All participants underwent clinical examinations to exclude any side effects to physical activity. 115 However, a medical certificate for competitive sport activities or noncompetitive sport activities was 116 requested. Moreover, subjects of all groups had the same main anthropometric characteristics (see 117 Table 1). The exclusion criteria were neuropathy, autonomic dysfunction, cardiovascular diseases. 118 All subjects (or their parents if $<18$ years) provided a written informed consent before the beginning 119 of the study. This study was conducted in accordance with the Declaration of Helsinki and approved by the CAR-IRB - University of Rome "Foro Italico" Committee (Approval N CAR 37/2020).

Table 1. Characteristics of the study sample (Mean value \pm SD)

\begin{tabular}{|c|c|c|c|c|}
\hline Parameters & All $(n=31)$ & $A(n=8)$ & B $(n=8)$ & $C(n=14)$ \\
\hline Age (years) & $15.7 \pm 2.7$ & $17.13^{ \pm} 4.22$ & $16.0 \pm 2.0$ & $14.3 \pm 1.6$ \\
\hline Height (cm) & $176.6 \pm 8.9$ & $183.85^{ \pm} 8.05$ & $174.6 \pm 6.7$ & $174.3 \pm 8.9$ \\
\hline Weight (kg) & $70.2 \pm 13.9$ & $73.5^{ \pm} \quad 7.7$ & $69.9 \pm 11.7$ & $68.6 \pm 17.8$ \\
\hline $\operatorname{BMI}\left(\mathrm{kg} / \mathrm{m}^{2}\right)$ & $22.3 \pm 3.4$ & $21.7 \pm \quad 1.3$ & $22.9 \pm 3.5$ & $22.3 \pm 4.2$ \\
\hline FM $\%$ & $20.9 \pm 5.9$ & $17.6^{ \pm} \quad 3.1$ & $21.0 \pm 6.5$ & $22.8 \pm 6.2$ \\
\hline
\end{tabular}

\section{Procedures}

125 After clinical examination and anthropometric measurements, all subjects performed an incremental exercise test on cycle-ergometer. All subjects were tested in the morning (between 9:00 and 12:00 
at the Department of Movement, Human and Health Sciences at the University of Rome "Foro

130 Italico".

\section{Anthropometric measurements}

132 The following participants' anthropometric measurements were assessed: body-weight, height, Body

133 Mass Index (BMI) and percent of fat mass (FM\%). Weight and height were measured using a scale

134 and a stadiometer to the nearest $0.1 \mathrm{~kg}$ and $0.1 \mathrm{~cm}$, respectively. BMI was calculated as the ratio

135 between weight in $\mathrm{kg}$ and the square of height in meters $\left(\mathrm{kg} / \mathrm{m}^{2}\right) . \mathrm{FM} \%$ was measured by bioelectrical 136 impedance method (BIA AKERN 101 Anniversary, Pontassieve, FI, Italy).

\section{Incremental exercise test}

The incremental exercise test on the cycle-ergometer was performed with the following protocol: participants started with a 1 minute rest period sitting on the bike, followed by 1 minute of unloaded pedaling ( 0 Watt). The workload was then increased by 20 Watts/minute for the A group (protocol

141 1) and by 15 Watts/minute for the $B$ and $C$ group (protocol 2), in order to maintain the total exercise time within about 15 minutes. Participants were asked to keep a cadence of 60-70 revolutions per one of the following conditions was reached: a value of 10 on OMNI Scale of Perceived Exertion, the $90 \%$ of the subject's predicted HRmax (beats/min) or a respiratory exchange ratio equal to 1.1 . The HR was recorded by a chest belt (HRM-Dual ${ }^{\mathrm{TM}}$, Garmin $\left.{ }^{\circledR}\right)$ contemporarily to Oxygen consumption $\left(\mathrm{VO}_{2}, \mathrm{~mL} / \mathrm{min}\right)$, carbon dioxide production $\left(\mathrm{VCO}_{2}, \mathrm{~mL} / \mathrm{min}\right)$, and pulmonary Cosmed ${ }^{\mathrm{TM}}$, Rome, Italy) [15].

\section{Detection of the AerT and AnT (GE method)}

152 Gas exchange method (GE) is the gold standard to detect both AerT and AnT as reported by Meyer 
by plotting the ventilatory equivalent of oxygen $\left(\mathrm{VE} / \mathrm{VO}_{2}\right)$ as a function of $\mathrm{VO}_{2}$ to identify the point

155 where the $\mathrm{VE} / \mathrm{VO}_{2}$ reached its lowest value during the exercise test [16-18]. This procedure was confirmed by a graph with $\mathrm{VCO}_{2}$ on the $\mathrm{y}$ axis and $\mathrm{VO}_{2}$ on the $\mathrm{x}$ axis: two regression lines are fitted for the upper and the lower part of the relation and their intersection represents the $\mathrm{AerT}_{\mathrm{GE}}(\mathrm{V}$-slope method, [5]).

159 Similarly, the $\mathrm{AnT}_{\mathrm{GE}}$ (that occurred at time named $\mathrm{T}_{2}$ ) was determined by plotting the ventilatory equivalent of carbon dioxide $\left(\mathrm{VE} / \mathrm{VCO}_{2}\right)$ as a function of $\mathrm{VO}_{2}$ to identify the point where the $\mathrm{VE} / \mathrm{VCO}_{2}$ reached its lowest value during the incremental test. This procedure was confirmed by a graph with $\mathrm{VE}$ on the $\mathrm{y}$ axis and $\mathrm{VCO}_{2}$ on the $\mathrm{x}$ axis: two regression lines are fitted for the upper and the lower part of the relation and their intersection represents the $\mathrm{AnT}_{\mathrm{GE}}[5]$.

$164 \mathrm{HR}$ e $\mathrm{VO}_{2}$ values corresponding at the two thresholds were reckoned as mean values of the last 30 165 seconds of the workload.

\section{Recurrence quantification analysis method (RQA)}

167 RQA can be defined as a graphical, statistical and analytical tool for the study of nonlinear dynamical system [19] and it is successfully used in a multitude of different disciplines from physiology [20(RQE), the rapid shifts from high to low (and vice versa) of percent of determinism (DET, the percentage of recurrence points which form diagonal lines) is usually an indicator of regime changes and phase transitions [25-26]. In fact, DET (High DET means high autocorrelation) is a universal marker of crisis in fields ranging from physiology to finance [27]. Laminarity (LAM, the percentage of recurrence points which form vertical lines), analogous to DET, measures the number of recurrence points which form vertical lines and indicates the amount of laminar phases (intermittency) in the system studied. In the present paper we use both ENT and LAM to study the increase in correlation and to identify the metabolic thresholds; the present study was focused on chaos-order transitions and 
physical fatigue was considered as an order parameter acting at physiological level. More details can be found at http://www.recurrence-plot.tk/ and in [26, 28-30].

\section{Data preprocessing}

182 As previously explained by Zimatore et al. (2020) [2], since the heart rate (HR) was continuously recorded and collected breath by breath, the time series of RR interval (temporal variation between the sequences of consecutive heartbeats) was reckoned by the ratio $60000 / \mathrm{HR}$. Moreover, since HR physiologically increases in relation to the workload, this physiological trend was removed in order to analyze the cardiac regime changes (detrended $R R$ interval) for each subject (the theoretical value of best linear fit on original time series were subtracted to every point belong to original time series). following same values were used:

RQA is computed across consecutive distance matrices corresponding to consecutive and overlapping sliding windows (epochs) along the series, and this mode of analysis is called RQE (Recurrence Quantification by the result is called RQA), plus the definition of windows having a length of 100 points ( 1 point correspond to 1 breath) and shifting of 1 point between consecutive windows, respectively.

RQA software, RQE.exe and RQC.exe version 8.1, are those included in RQA 14.1 [28]. RQE on sliding windows partially overlapped are carried on a detrended RR interval and then RQA measures are obtained. 
The method of threshold detection based on RQA of RR intervals (HRV time series) can be described

as follows: specifically, AerT $\mathrm{RQA}_{\mathrm{R}}$ was determined by the time point when the statistically relevant

minimum of percent of determinism and laminarity occurred. $\mathrm{AnT}_{\mathrm{RQA}}$, instead, occurred when

changes in RP texture (see Fig 1). $\mathrm{HR}$ e $\mathrm{VO}_{2}$ values corresponding to the two thresholds were

reckoned as mean values on the last 10 values of the original time series before the value

corresponding to the two threshold times $\left(\mathrm{T}_{1}\right.$ and $\left.\mathrm{T}_{2}\right)$.

Figure 1. RP and RQE comparison. A comparison among two representative RP is shown in panel a (subject \#1) and panel c (subject \#3). Panel b (subject \#1) and panel d (subject \#3) show the percentage of recurrence points which form diagonal lines (DET) and the percentage of recurrence points which form vertical lines (LAM) epoch by epoch vs time (min:sec) of detrended RR interval.

The red line enlightens the statistically relevant minimum that corresponds to the AerT and the green line corresponds to the AnT where the percent of determinism reaches saturation. Subject \#1 is a competitive rower (group A, protocol 1) and subject \#3 is a recreational rower (group B, protocol 2). The test starts at 00:00; AerT occurred at time $T_{1}, 8: 38$ and 5:49 for \#1 and \#3, respectively; AnT occurred at time $\mathrm{T}_{2}, 11: 24$ and 11:01 for \#1 and \#3, respectively. A square pattern in the middle is easily distinguishable, the vertical red line is manually placed nearby before the first metabolic transition, the green one nearby before the second one. The colors of RP reflect different Euclidean distances between trajectories and are analogous to geographical relief maps going from blue to red at increasing Euclidean distance. Distances greater than cut-off correspond to black regions.

\section{Statistical analysis}

227 Repeated measures analysis of variance (RM ANOVA) was used to assess main effects of methods

(RQA vs GE) and methods-by-groups (A, B and C) interaction effects for $\mathrm{HR}, \mathrm{VO}_{2}$ and Workload at

the AerT and the AnT. Agreements between RQA and GE methods at the AerT and the AnT were

assessed for $\mathrm{HR}, \mathrm{VO}_{2}$ and Workload by Ordinary Least Products (OLP) regression analysis [31].

231 Coefficients of determination $\left(\mathrm{R}^{2}\right)$ and regression parameters (slope and intercept) with the $95 \%$ of 232 confidence intervals $(95 \% \mathrm{CI})$ were calculated for the OLP regression equation to determine fixed 233 and proportional biases. The hypothesis of proportional and fixed bias was rejected when the $95 \% \mathrm{CI}$

234 contained the value 1 for the slope and the 0 for the intercept, respectively. Percentage differences 235 between the RQA and GE methods at the AerT and the AnT (reported as mean and range values) 236 were calculated for $\mathrm{HR}, \mathrm{VO}_{2}$ and Workload. RQA method validity was also assessed by comparing $237 \mathrm{HR}, \mathrm{VO}_{2}$ and Workload at the AerT and the AnT vs the same variables measured by the GE method 
with a paired samples t-test. Measurement error was expressed in Typical percentage Error (TE) which was calculated by dividing the standard deviation of the difference percentage by $\sqrt{2}$. Intraclass correlation coefficients (ICC) was used as a parameter for criterion validity of the RQA method compared to the GE method at the AerT and the AnT for all variables ( $\mathrm{HR}, \mathrm{VO}_{2}$ and Workload).

Bland-Altman plots were applied to determine the 95\% CI between the RQA and GE methods at the AerT and the AnT for the HR [32].

Statistical significance was defined as $\mathrm{p} \leq 0.05$. All statistical analysis was performed by SPSS version 24.0 software (SPSS Inc., Chicago, IL).

\section{Results}

Workload at the AerT and $\mathrm{HR}, \mathrm{VO}_{2}$, and Workload at the AnT were not statistically different between RQA and GE methods. Significant differences were found between the two methods for HR at the AerT $\left(\mathrm{HR}\right.$ at the $\operatorname{AerT}_{\mathrm{GE}}=137.77 \pm 15.25$ beats $/ \mathrm{min}$; HR at the $\operatorname{AerT}_{\mathrm{RQA}}=141.44 \pm 15.35$ beats $/ \mathrm{min}$ ) and for $\mathrm{VO}_{2}$ at the AerT $\left(\mathrm{VO}_{2}\right.$ at the AerT $\mathrm{GE}=1849.56 \pm 477.68 \mathrm{~mL} / \mathrm{min} ; \mathrm{VO}_{2}$ at the $\left.\operatorname{AerT}_{\mathrm{RQA}}=1945.37 \pm 516.91 \mathrm{~mL} / \mathrm{min}\right)$. No methods-by-groups interaction effects were detected for $\mathrm{HR}, \mathrm{VO}_{2}$ and Workload at the AerT and the AnT (Table 2).

Table 2. Main effects of methods (RQA vs GE) and method-by-group (A, B and C) interaction effects in HR, VO2 and Workload at AerT and AnT (ANOVA RM)

\begin{tabular}{llcc} 
Parameter & Effect & AerT & AnT \\
\hline HR (beats(min) & Method & $0.026^{*}$ & 0.466 \\
& Method-by-group & 0.766 & 0.789 \\
\hline $\mathbf{V O}_{\mathbf{2}}(\mathbf{m L} / \mathbf{m i n})$ & Method & $0.020^{*}$ & 0.334 \\
& Method-by-group & 0.717 & 0.746 \\
\hline Workload (Watt) & Method & 0.115 & 0.288 \\
& Method -by-group & 0.261 & 0.765 \\
\hline
\end{tabular}

*p<0.05 


\section{$\mathrm{HR}, \mathrm{VO}_{2}$ and Workload at AerT}

260 The agreements between $\mathrm{HR}, \mathrm{VO}_{2}$ and Workload at the $\mathrm{AerT}_{\mathrm{GE}}$ and the $\mathrm{AerT}_{\mathrm{RQA}}$ are presented in

261 Table 3. In all variables ( $\mathrm{HR}, \mathrm{VO}_{2}$ and Workload) OLP regression analysis showed that the AerT $\mathrm{TE}_{\mathrm{GE}}$

262 and the Aer $\mathrm{T}_{\mathrm{RQA}}$ had very strong correlations $(r>0.8)$. Slope and intercept values always included

263 the 1 and the 0, respectively. Mean percentage differences ranged from $2.67 \%$ to $5.18 \%$ (HR and

$264 \mathrm{VO}_{2}$, respectively). $\mathrm{HR}$ and $\mathrm{VO}_{2}$ at the AerT resulted statistically different between the two evaluation methods $(p<0.05)$ while no differences were assessed for Workload at the AerT. The TE for HR and $\mathrm{VO}_{2}$ at the AerT was considered acceptable (4.02\% and 8.40\%, respectively), moreover the TE for the Workload at AerT (10.47\%) was slightly higher than the acceptable 10\% limit [33]. ICC values were excellent $(\geq 0.85)$ for all variables at the AerT [34-35]. The OLP regression analysis plots of $\mathrm{HR}, \mathrm{VO}_{2}$ and Workload values at the $\mathrm{AerT}_{\mathrm{GE}}$ and at the $\mathrm{AerT}_{\mathrm{RQA}}$ are graphically shown in Figs 2a,

(solid line), the identity (dashed line), the equation, the correlation coefficient $(r)$ and the absolute mean differences. For the HR the Bland-Altman plot with the mean difference in the solid line (3.7 beats/min) and the $95 \% \mathrm{CI}$ in the dashed lines (- 1.5 to 18.9 beats/min) is shown in the upper-left panel of Fig 2a.

Table 3. Agreement between $\mathrm{HR}, \mathrm{VO}_{2}$ and Workload values at AerT and AnT estimated by GE and RQA methods.

\begin{tabular}{|c|c|c|c|c|c|c|c|}
\hline Parameter (threshold) & $\mathbf{R}^{2}$ & $\begin{array}{c}\text { Slope } \\
(95 \% \text { CI }) \\
\end{array}$ & $\begin{array}{l}\text { Intercept } \\
(95 \% \text { CI })\end{array}$ & $\begin{array}{c}\text { Mean diff (\%) } \\
(95 \% \mathrm{CI})\end{array}$ & $p$ & TE (\%) & $\begin{array}{c}\text { ICC } \\
(95 \% \mathrm{CI}) \\
\end{array}$ \\
\hline HR (AerT) & 0.760 & $\begin{array}{c}1.01 \\
(0.82 \text { to } 1.23)\end{array}$ & $\begin{array}{c}2.83 \\
(-27.74 \text { to } 27.87)\end{array}$ & $\begin{array}{c}2.83 \\
\text { (0.80 to } 4.87)\end{array}$ & $0.014 *$ & 4.02 & $\begin{array}{c}0.85 \\
(0.68 \text { to } 0.93)\end{array}$ \\
\hline $\mathrm{VO}_{2}(\mathrm{AerT})$ & 0.846 & $\begin{array}{c}1.08 \\
(0.92 \text { to } 1.27)\end{array}$ & $\begin{array}{c}-56.09 \\
(-404.00 \text { to } 240.30)\end{array}$ & $\begin{array}{c}5.59 \\
(1.34 \text { to } 9.84)\end{array}$ & $0.015^{*}$ & 8.40 & $\begin{array}{c}0.90 \\
(0.78 \text { to } 0.96)\end{array}$ \\
\hline Workload (AerT) & 0.908 & $\begin{array}{c}1.03 \\
\text { (0.91 to } 1.17)\end{array}$ & $\begin{array}{c}1.30 \\
(-11.411 \text { to } 12.523)\end{array}$ & $\begin{array}{c}5.26 \\
(-0.04 \text { to } 10.55)\end{array}$ & 0.080 & 10.47 & $\begin{array}{c}0.95 \\
(0.89 \text { to } 0.98)\end{array}$ \\
\hline HR (AnT) & 0.792 & $\begin{array}{c}0.96 \\
(0.80 \text { to } 1.16)\end{array}$ & $\begin{array}{c}5.51 \\
(-26.62 \text { to } 32.19)\end{array}$ & $\begin{array}{c}-0.33 \\
(-1.65 \text { to } 0.99)\end{array}$ & 0.524 & 2.61 & $\begin{array}{c}0.89 \\
(0.78 \text { to } 0.95)\end{array}$ \\
\hline $\mathrm{VO}_{2}(\mathrm{AnT})$ & 0.941 & $\begin{array}{c}0.914 \\
(0.83 \text { to } 1.010)\end{array}$ & $\begin{array}{c}183.73 \\
(-54.17 \text { to } 399.02)\end{array}$ & $\begin{array}{c}-0.83 \\
(-3,24 \text { to } 1.59)\end{array}$ & 0.319 & 4.78 & $\begin{array}{c}0.97 \\
(0.93 \text { to } 0.98)\end{array}$ \\
\hline Workload (AnT) & 0.947 & $\begin{array}{c}0.94 \\
(0.86 \text { to } 1.03)\end{array}$ & $\begin{array}{c}11.09 \\
(-2.42 \text { to } 23.40)\end{array}$ & $\begin{array}{c}2.82 \\
(-0.54 \text { to } 6.18)\end{array}$ & 0.225 & 6.64 & $\begin{array}{c}0.97 \\
(0.94 \text { to } 0.99)\end{array}$ \\
\hline
\end{tabular}


Determinant coefficient $\left(\mathrm{R}^{2}\right)$, slope and intercept of the regression equations, mean percentage differences (mean diff $\%), p$ values, typical percentage error (TE), confidence interval (IC) and intra-class correlation coefficient (ICC). $* \mathrm{p}<0.05$

Fig 2. Regression and difference (Bland- Altman) plots of HR estimated by RQA and GE methods at AerT (a) and AnT (b).

Fig 3. Regression plots of $\mathrm{VO}_{2}$ estimated by RQA and GE methods at AerT (a) and AnT (b).

Fig 4. Regression plots of Workload estimated by RQA and GE methods at AerT (a) and AnT (b).

\section{$\mathrm{HR}, \mathrm{VO}_{2}$ and Workload at AnT}

The agreement between $\mathrm{HR}, \mathrm{VO}_{2}$ and Workload at the $\mathrm{AnT}_{\mathrm{GE}}$ and the $\mathrm{AnT}_{\mathrm{RQA}}$ are presented in Table 3. In all variables ( $\mathrm{HR}, \mathrm{VO}_{2}$ and Workload) OLP regression analysis showed that the $\mathrm{AnT}_{\mathrm{GE}}$ and the $\mathrm{AnT}_{\mathrm{RQA}}$ had very strong correlations $(r>0.8)$ [36]. Slope and intercept values always included the 1 and the 0 , respectively. Mean percentage differences ranged from $-0.42 \%$ to $1.72 \%$ (HR and Workload, respectively) and all variables corresponding to the AnT did not result statistically different between the two evaluation methods. For $\mathrm{HR}, \mathrm{VO}_{2}$ and Workload at the AnT the TE was considered acceptable $(2.61 \%, 4.78 \%$ and $6.64 \%$, respectively) and ICC values were excellent $(\geq 0.89)$ [33-35]. The OLP regression analysis plots of $\mathrm{HR}, \mathrm{VO}_{2}$ and Workload at the $\mathrm{AnT}_{\mathrm{GE}}$ and at the $\mathrm{AnT}_{\mathrm{RQA}}$ are graphically shown in Figs $2 \mathrm{~b}, 3 \mathrm{~b}$ and $4 \mathrm{~b}$, respectively. For the HR the Bland-Altman plot with the mean difference $(-0.7)$ and the $95 \% \mathrm{CI}(-12.1$ to 10.7 beats/min) is shown in the upperleft panel of Fig $2 b$.

\section{Discussion}

The first aim of the study was to verify if in individuals with different physical fitness levels the new non-linear method based on RQA could be an alternative to gas analysis in the determination of metabolic thresholds. The second aim was to verify the validity of the RQA method compared to the GE method in thresholds detection. To our knowledge, this is the first study assessing the accuracy of the RQA method during the determination of both the AerT and the AnT. In particular, in the present investigation we examined the RQA epoch-by-epoch procedure in order to analyze HRV time 
series during phase transition. The RQA method is a graphical and analytical approach which has been successfully used in a multitude of different fields as earth science [22], economics [23-24] and physiological signals as otoacoustic emissions [20-21]. However, this methodology still needs to be deeply investigated in the field of exercise testing.

Even though for $\mathrm{HR}$ and $\mathrm{VO}_{2}$ at the AerT significant differences were found between the two methodologies (RQA and GE methods), no differences were detected for Workload at the AerT and for $\mathrm{HR}, \mathrm{VO}_{2}$ and Workload at the AnT. Furthermore, the absence of methods-by-group interactions in all variables at both the thresholds indicated that the RQA method is not influenced by the level of physical fitness of the subjects. Therefore, this method can be applied in individuals practicing different sports and with different physical fitness levels in situations where gas analysis is not available. These results permitted us to move to the second aim of the study which consisted in verifying the validity of the RQA method against the GE method during thresholds identification through different validation parameters (OLP regression, TE, ICC, and the Bland Altman plots) individually for $\mathrm{HR}, \mathrm{VO}_{2}$ and Workload variables corresponding at the AerT and the AnT.

Regarding the degree of agreement between the two methods of AerT detection (AerT $_{\mathrm{GE}}$ and AerT $\mathrm{RQA}_{\mathrm{RA}}$ ), all variables (HR, $\mathrm{VO}_{2}$ and Workload) showed very strong correlations [36]. Neither fixed or proportional biases were present in all parameters and mean percentage differences were less than $5 \%$ for $\mathrm{HR}$ and Workload and less than $6 \%$ for $\mathrm{VO}_{2}$. As observed in the RM ANOVA results, HR and $\mathrm{VO}_{2}$ at the AerT showed significant differences between the two methods. However, both these parameters showed an acceptable TE (HR 4.02\%; $\mathrm{VO}_{2} 8.40 \%$ ) and excellent ICC values (HR 0.85; $\mathrm{VO}_{2}$ 0.90) [33-35]. Therefore, for all these reasons the statistical differences detected between the two methods can be considered not relevant for practical applications. In particular, the low percentage of TE in the heart rate indicated that this variable at the $A_{e r} T_{R Q A}$ represents the most accurate parameter to be monitored. To conclude, the Workload corresponding to the AerT did not result statistically different between the two evaluation methods and showed in the ICC an excellent 
value of 0.95 [34-35]. However, this parameter showed a TE slightly higher than the acceptable limit

$333(10.47 \%)[33]$.

334 These first results about the validity of the RQA method for the detection of the AerT could be 335 summarized stating that the Aer $_{\mathrm{RQA}}$ is a valid method to use as alternative of gas analysis. In 336 particular, the heart rate at AerT is considered the most valid parameter to monitor using the RQA 337 method, and the determination of the AerT with this approach loses accuracy with $\mathrm{VO}_{2}$ and Workload 338 variables. Between the different exercise variables, the HR seems to be not only the most accurate 339 but also the most sustainable, indeed this parameter can be easily recorded during training using non340 invasive, not expensive, time-efficient devices which can be applied routinely and simultaneously in 341 a large number of athletes [13]. In the field of exercise assessment, the heart rate variability has been 342 largely used to identify the AerT in several specific populations as diabetic and cardiac patients [37343 38], healthy individuals [39-40], competitive cyclists and triathletes [41], and professional soccer 344 players [11]. However, little is known about the accuracy of the alternative approach of the RQA of 345 HRV time series. Indeed, this method so far has been used only for the identification of the AerT in 346 obese subjects [2]. The present work enlarges the boundaries of this methodology confirming the 347 efficacy of RQA analysis also in individuals with a higher physical fitness level. Therefore, the 348 utilization of the Aer $_{\mathrm{RQA}}$ may provide an important training intensity guidance for the identification 349 of the exercise zone which can be covered predominantly by the aerobic metabolism $[4,5,17]$.

350 In terms of degree of agreement between $\mathrm{AnT}_{\mathrm{GE}}$ and $\mathrm{AnT}_{\mathrm{RQA}}$, all parameters (HR, VO2 and 351 Workload) showed very strong correlations [36] and neither fixed or proportional biases were 352 detected. In addition, mean percentage differences were less than $1 \%$ for HR and less than $2 \%$ for 353 Workload and $\mathrm{VO}_{2}$ and no significant differences were found in all variables. Moreover, the 354 acceptable TE values (HR 2.61\%; $\mathrm{VO}_{2} 4.78 \%$, Workload 6.64\%) and the excellent ICC values (HR 355 0.89; VO2 0.97; Workload 0.97) confirmed the validity of all parameters corresponding at the $356 \mathrm{AnT}_{\mathrm{RQA}}[33-36]$. As it was observed in the AerT, the lowest TE found in HR demonstrated that this 357 parameter is the most accurate to use for the detection of the AnT with the RQA method. 
Based on the aforementioned findings we believe that the RQA approach is a valid method as an

359 alternative to gas analysis in the determination of the AnT. In addition, comparing the accuracy of

360 the different variables, the heart rate at the AnT seems to be the most valid and sustainable parameter

361 to use with the RQA method. The HRV has been utilized to estimate the AnT in different exercise 362 evaluation fields [7-12, 38, 41-42]. However, to our knowledge, this is the first study which attempted 363 to directly examine the non-linear approach of the RQA of HRV time series in the estimation of the 364 AnT. Considering the high importance that the AnT detection has for sport performance [5, 7-8], these results may provide a useful contribution in training prescription and evaluation.

Even though we suggested the use of RQA method as a COVID-safe alternative to gas analysis for the detection of both metabolic thresholds, comparing the validity of the $\mathrm{Aer}_{\mathrm{RQA}}$ and $\mathrm{AnT}_{\mathrm{RQA}}$ (with OLP regression, TE, ICC and the Bland Altman plots) it appeared that the $\mathrm{AnT}_{\mathrm{RQA}}$ has a better accuracy than Aer $_{\mathrm{RQA}}$ and other studies showed similar results [9-10, 43]. This lower accuracy in the $A_{e r} T_{\mathrm{RQA}}$ may be explained by methodological problems in the determination of this threshold using gas analyzers. Indeed, it seems that the accuracy, the intra- and inter-observer reliability, the repeatability and the percentage of indeterminate thresholds of the AerT $\mathrm{GE}_{\mathrm{GE}}$ had been questioned [5, 43]. Therefore, the lower agreement between Aer $_{\mathrm{RQA}}$ and $\mathrm{AerT}_{\mathrm{GE}}$ may be caused by methodological problems on the GE method in some particular individuals. In view of all these aspects, the use of the RQA method could be used as a supportive approach to gas analysis for all the cases in which the detection of the AerT is ambiguous.

The following limitations are acknowledged. First, the number of participants in the study was relatively small. Second, the population was not heterogeneous (composed by 28 males and only 2 [44], further research should investigate the RQA of HRV time series separately in males and females.

381 In addition, future physiological exercise studies should assess if the findings of the present work could be adopted in particular field tests which do not necessarily require the use of a cycle-ergometer. 


\section{Conclusion}

385 The recurrence quantification analysis of heart rate variability time series is a COVID-safe approach 386 for the determination of metabolic thresholds in individuals with different physical fitness levels, 387 therefore, it can be used as a valid method for threshold detection alternative to gas analysis. Thus, in 388 on-field evaluation, during an incremental exercise test it is possible to assess sport performance and 389 delineate the intensity of training zones using non-invasive and low-cost devices. Based on the 390 present results, coaches could obtain information about the training trend of their athletes avoiding 391 classical respiratory measurement devices which require specific knowledge and that may be not 392 allowed during this particular pandemic period.

\section{References} Heart. 2007;93(10): 1285-92. doi: 10.1136/hrt.2007.121558

3972 Zimatore G, Gallotta MC, Innocenti L, Bonavolontà V, Ciasca G, De Spirito et al. Recurrence 398 quantification analysis of heart rate variability during continuous incremental exercise test in obese subjects. 399 Chaos. 2020;30(3): 033135. doi: 10.1063/1.5140455

4003 Emerenziani GP, Gallotta MC, Migliaccio S, Ferrari D, Greco EA, Saavedra FJ et al. Effects of an 401 individualized home-based unsupervised aerobic training on body composition and physiological parameters 402 in obese adults are independent of gender. J Endocrinol Invest. 2018;41(4): 465-473. doi: 10.1007/s40618$403 \quad 017-0771-2$

4044 Skinner JS, McLellan TH. The transition from aerobic to anaerobic metabolism. Res Q Exerc Sport 405 1980;51 (1): 234-48. doi: 10.1080/02701367.1980.10609285 
5 Meyer T, Lucía A, Earnest CP, Kindermann W. A conceptual framework for performance diagnosis and training prescription from submaximal gas exchange parameters--theory and application. Int J Sports Med. 2005;26 Suppl 1: S38-48. doi: 10.1055/s-2004-830514

6 Emerenziani G.P, Migliaccio S., Gallotta M.C, Lenzi A, Baldari C, Guidetti L. Physical exercise intensity prescription to improve health and fitness in overweight and obese subjects: a review of the literature. Health. 2013;5(6A2): 113-121. doi:10.4236/health.2013.56A2017 7 Conconi F, Ferrari M, Ziglio PG, Droghetti P, Codeca L. Determination of the anaerobic threshold by} a noninvasive field test in runners. J Appl Physiol Respir Environ Exerc Physiol. 1982;52(4): 869-73. doi: 10.1152/jappl.1982.52.4.869

8 Cabo JV, Martinez-Camblor P, Del Valle M. Validity of the modified conconi test for determining ventilatory threshold during on-water rowing. J Sports Sci Med. 2011;1;10(4): 616-23. PMID: 24149549;PMCID: PMC3761509

9 Cassirame J, Tordi N, Fabre N, Duc S, Durand F, Mourot L. Heart rate variability to assess ventilatory threshold in ski-mountaineering. Eur J Sport Sci. 2014;15(7): 615-22. doi: 10.1080/17461391.2014.957729

10 Giovanelli N, Scaini S, Billat V, Lazzer S. A new field test to estimate the aerobic and anaerobic thresholds and maximum parameters. Eur J Sport Sci. 2020;20(4): 437-443. doi: $10.1080 / 17461391.2019 .1640289$

11 Cottin F, Médigue C, Lopes P, Leprêtre PM, Heubert R, Billat V. Ventilatory thresholds assessment from heart rate variability during an incremental exhaustive running test. Int J Sports Med. 2007;28(4): 28794. doi: $10.1055 / \mathrm{s}-2006-924355$

12 Buchheit M, Solano R, Millet GP. Heart-rate deflection point and the second heart-rate variability threshold during running exercise in trained boys. Pediatr Exerc Sci. 2007;19(2): 192-204. doi: 10.1123/pes.19.2.192

13 Buchheit M. Monitoring training status with HR measures: do all roads lead to Rome? Front Physiol. 2014;27;5:73. doi: 10.3389/fphys.2014.00073

14 Robertson RJ, Goss FL, Dube J, Rutkowski J, Dupain M, Brennan C et al. Validation of the adult OMNI scale of perceived exertion for cycle ergometer exercise. Med Sci Sports Exerc. 2004;36(1): 102-8. doi: 10.1249/01.MSS.0000106169.35222.8B

15 Nieman DC, Austin MD, Dew D, Utter AC. Validity of COSMED's quark CPET mixing chamber system in evaluating energy metabolism during aerobic exercise in healthy male adults. Res Sports Med. 2013;21(2): 136-45. doi: 10.1080/15438627.2012.757227 

production during incremental load work. Int J Sports Med. 1984;5(4): 193-7. doi: 10.1055/s-2008-1025904

43917 Hollmann W. 42 years ago--development of the concepts of ventilatory and lactate threshold. Sports 440 Med. 2001;31(5): 315-20. doi: 10.2165/00007256-200131050-00002

$441 \quad 18$ Baldari C, Guidetti L. A simple method for individual anaerobic threshold as predictor of max lactate 442 steady state. Med Sci Sports Exerc. 2000;32(10): 1798-802. doi: 10.1097/00005768-200010000-00022

44319 Webber CL Jr, Zbilut JP. Dynamical assessment of physiological systems and states using recurrence 444 plot strategies. J Appl Physiol. 1994;76(2): 965-73. doi: 10.1152/jappl.1994.76.2.965

44520 Zimatore G, Cavagnaro M. Recurrence Analysis of Otoacoustic Emissions. In Recurrence 446 Quantification Analysis: Theory and Best Practices. 2015;253-278. ISBN : 978-3-319-07154-1

44721 Zimatore G, Cavagnaro M, Skarzynski PH, Fetoni AR, Hatzopoulos S. Detection of Age-Related 448 Hearing Losses (ARHL) via Transient-Evoked Otoacoustic Emissions. Clin Interv Aging. 2020;15:927-935. 449 doi: $10.2147 /$ CIA.S252837

45022 Zimatore G, Garilli G, Poscolieri M, Rafanelli C, Terenzio Gizzi F et al. The remarkable coherence 451 between two Italian far away recording stations points to a role of acoustic emissions from crustal rocks for 452 earthquake analysis. Chaos. 2017;27(4): 043101. doi: 10.1063/1.4979351

45323 Orlando G, Zimatore G. Recurrence quantification analysis of business cycles. Chaos, Solitons and 454 Fractals. 2018;110, 82-94. https://doi.org/10.1016/j.chaos.2018.02.032

45524 Orlando G, Zimatore G. Business cycle modeling between financial crises and black swans: Ornstein456 Uhlenbeck stochastic process vs Kaldor deterministic chaotic model. Chaos. 2020;30(8): 083129. doi: $457 \quad 10.1063 / 5.0015916$

45825 Trulla L, Giuliani A, Zbilut J P, Webber Jr C L. Recurrence quantification analysis of the logistic 459 equation with transients. Phys Lett A. 1996;223(4): 255-260. https://doi.org/10.1016/S0375-9601(96)00741$460 \quad 4$

46126 Marwan N, Romano M C, Thiel M, Kurths J. Recurrence plots for the analysis of complex systems. 462 Phy. Rep. 2007;438(5-6): 237-329

46327 Gorban A N, Smirnova E V, Tyukina T A. Correlations, risk and crisis: From psychology to finance. 464 Physica A. 2010;389(16), 3193-3217. https://doi.org/10.1016/j.physa.2010.03.035 
28 Webber, C. L., see http://homepages.luc.edu/cwebber for RQC.exe and RQE.exe files belong to RQA ver. 8.1 are included in RQA software ver.14.1 (2012) (last accessed 15th January 2020)

46729 Zbilut JP, Thomasson N, Webber CL. Recurrence quantification analysis as a tool for nonlinear 468 exploration of nonstationary cardiac signals. Med Eng Phys. 2002;24(1): 53-60. doi: 10.1016/s13504533(01)00112-6

47030 Marwan N, Zou Y, Wessel N, Riedl M, Kurths J. Estimating coupling directions in the 471 cardiorespiratory system using recurrence properties. Philos Trans A Math Phys Eng Sci. 2013;371(1997): 472 20110624. doi: 10.1098/rsta.2011.0624

47331 Guidetti L, Meucci M, Bolletta F, Emerenziani GP, Gallotta MC, Baldari C. Validity, reliability and 474 minimum detectable change of COSMED K5 portable gas exchange system in breath-by-breath mode. PLoS 475 One. 2018;31;13(12): e0209925. doi: 10.1371/journal.pone.0209925

47632 Bland JM, Altman DG. Statistical methods for assessing agreement between two methods of clinical 477 measurement. Lancet. 1986;8;1(8476): 307-10. https://doi.org/10.1016/S0140-6736(86)90837-8

47833 Alexander D L J, Tropsha A, Winkler D A. Beware of R²: Simple, Unambiguous Assessment of the 479 Prediction Accuracy of QSAR and QSPR Models. J. Chem. Inf. Model. 2015;55, 1316- 1322. doi: $480 \quad 10.1021 /$ acs.jcim.5b00206

$48134 \quad$ Cicchetti D V \& Sparrow S A. Developing criteria for establishing interrater reliability of specific 482 items: Applications to assessment of adaptive behavior. American Journal of Mental Deficiency. 1981;86 (2), 483 127-137. PMID: 7315877

48435 Perinetti G. StaTips Part IV: Selection, interpretation and reporting of the intraclass correlation 485 coefficient. South Eur J Orthod Dentofac Res. 2018;5(1): 3-5.

48636 Chan YH. Biostatistics 104: correlational analysis. Singapore Med J. 2003;44(12): 614-9. PMID: $487 \quad 14770254$

48837 Sales MM, Campbell CS, Morais PK, Ernesto C, Soares-Caldeira LF, Russo P et al. Noninvasive 489 method to estimate anaerobic threshold in individuals with type 2 diabetes. Diabetol Metab Syndr. 2011;3(1): 490 1. doi: $10.1186 / 1758-5996-3-1$

49138 Mourot L, Tordi N, Bouhaddi M, Teffaha D, Monpere C, Regnard J. Heart rate variability to assess 492 ventilatory thresholds: reliable in cardiac disease? Eur J Prev Cardiol. 2012;19(6): 1272-80. doi: $493 \quad 10.1177 / 1741826711423115$ 
49640 Rogers B, Giles D, Draper N, Hoos O, Gronwald T. A New Detection Method Defining the Aerobic 497 Threshold for Endurance Exercise and Training Prescription Based on Fractal Correlation Properties of Heart 498 Rate Variability. Front Physiol. 2021;11: 596567. doi: 10.3389/fphys.2020.596567

49941 Cottin F, Leprêtre PM, Lopes P, Papelier Y, Médigue C, Billat V. Assessment of ventilatory thresholds 500 from heart rate variability in well-trained subjects during cycling. Int J Sports Med. 2006;27(12): 959-67. doi: $501 \quad 10.1055 / \mathrm{s}-2006-923849$

50242 Merati G, Rampichini S, Cè E, Sangiovanni M, Castiglioni P, Di Rienzo M et al. Ventilatory threshold 503 detection: a new method based on heart rate variability. Computers in Cardiology, 2004, Chicago, IL, USA. 504 2004; pp. 221-224. doi: 10.1109/CIC.2004.1442912

50543 Zignoli A, Fornasiero A, Rota P, Muollo V, Peyré-Tartaruga L A, Low D A, Fontana F Y, Besson D, 506 Pühringer M, Ring-Dimitriou S \& Mourot L. Oxynet: A collective intelligence that detects ventilatory 507 thresholds in cardiopulmonary exercise tests. Eur J Sport Sci. 2021;1-11. doi: $508 \quad 10.1080 / 17461391.2020 .1866081$

50944 Ansdell P, Thomas K, Hicks KM, Hunter SK, Howatson G, Goodall S. Physiological sex differences 510 affect the integrative response to exercise: acute and chronic implications. Exp Physiol. 2020;105(12): 2007511 2021. doi: 10.1113/EP088548 


\section{List of abbreviations}

514 HR Heart Rate

515 HRV Heart Rate Variability

516 CPET Cardiopulmonary exercise test

517 RPE Rate of Perceived Exertion

518 RQA Recurrence Quantification Analysis

519 GE Gas Exchange

520 AerT $_{\mathrm{GE}}$ Aerobic Gas Exchange Threshold

$521 \quad \mathrm{AnT}_{\mathrm{GE}}$ Anaerobic Gas Exchange Threshold

522 AerT $_{\mathrm{RQA}}$ Aerobic Recurrence Quantification Analysis Threshold

$523 \mathrm{AnT}_{\mathrm{RQA}}$ Anaerobic Recurrence Quantification Analysis Threshold

524 DET percent of determinism, the percent of recurrence points which form diagonal lines

525 LAM percent of laminarity, the percent of recurrence points which form vertical lines

526 BMI Body Mass Index

527 BIA Bioelectrical Impedance Analysis

528 FM\% Fat Mass percentage

$529 \mathrm{VO}_{2}$ Volume of Oxygen consumption

$530 \mathrm{VCO}_{2}$ Volume of Carbon dioxide production

531 VE ventilation

532 OLP Ordinary Least Product

533 TE Typical percentage Error

534 ICC Intraclass correlation coefficients

535 IC confidence interval 
b)

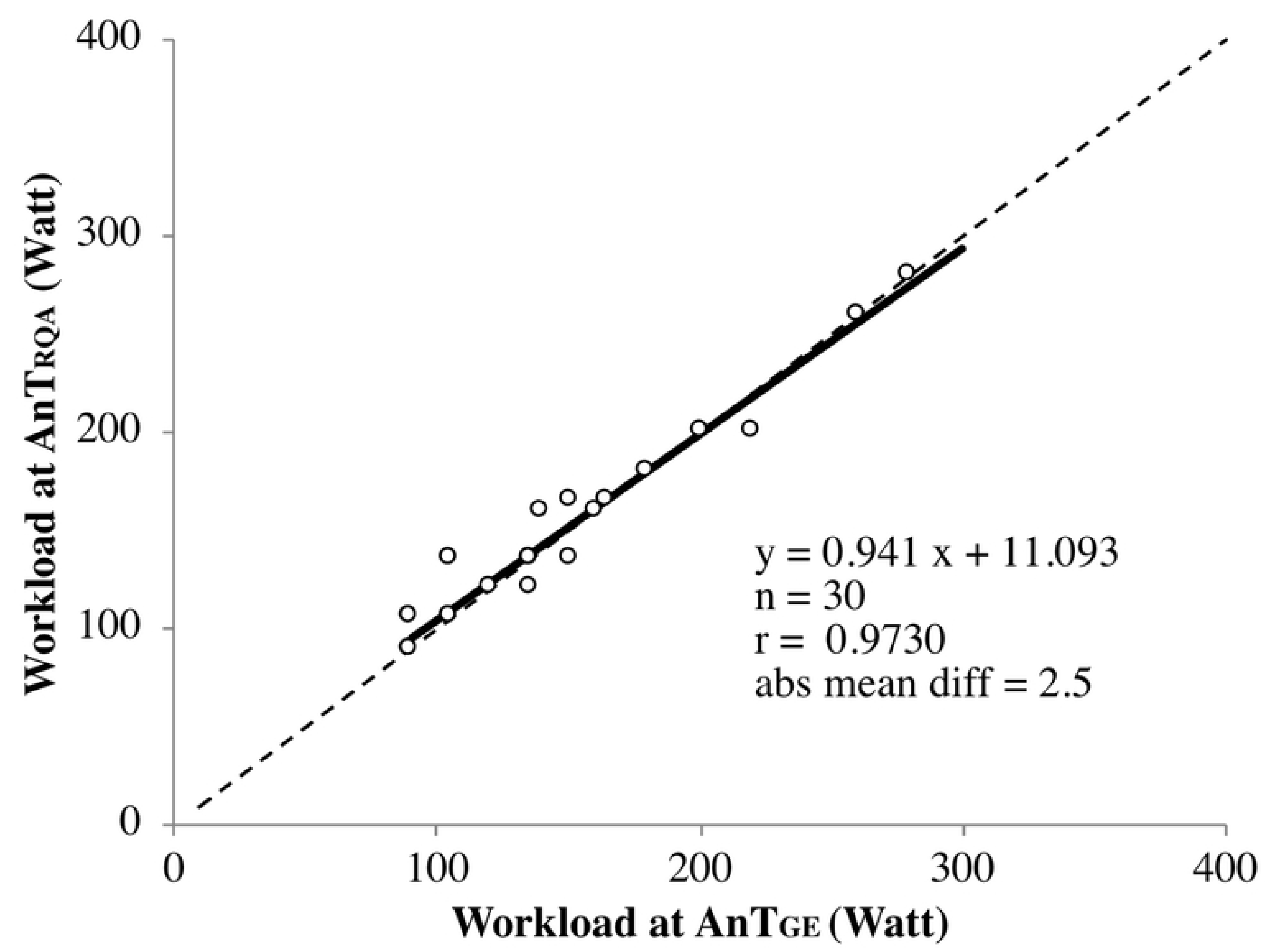

fig $4 \mathrm{~b}$ 
a)

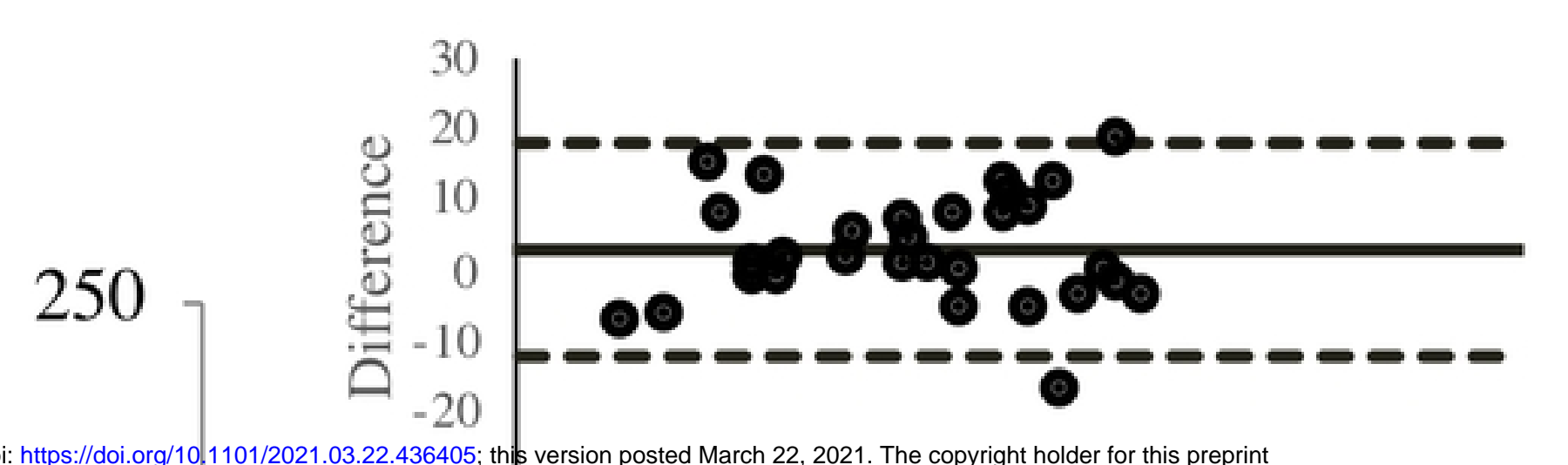

bioRxiv preprint doi: https://doi.org/10.1101/2021.03.22.436405; th s version posted March 22, 2021. The copyright holder for this preprint

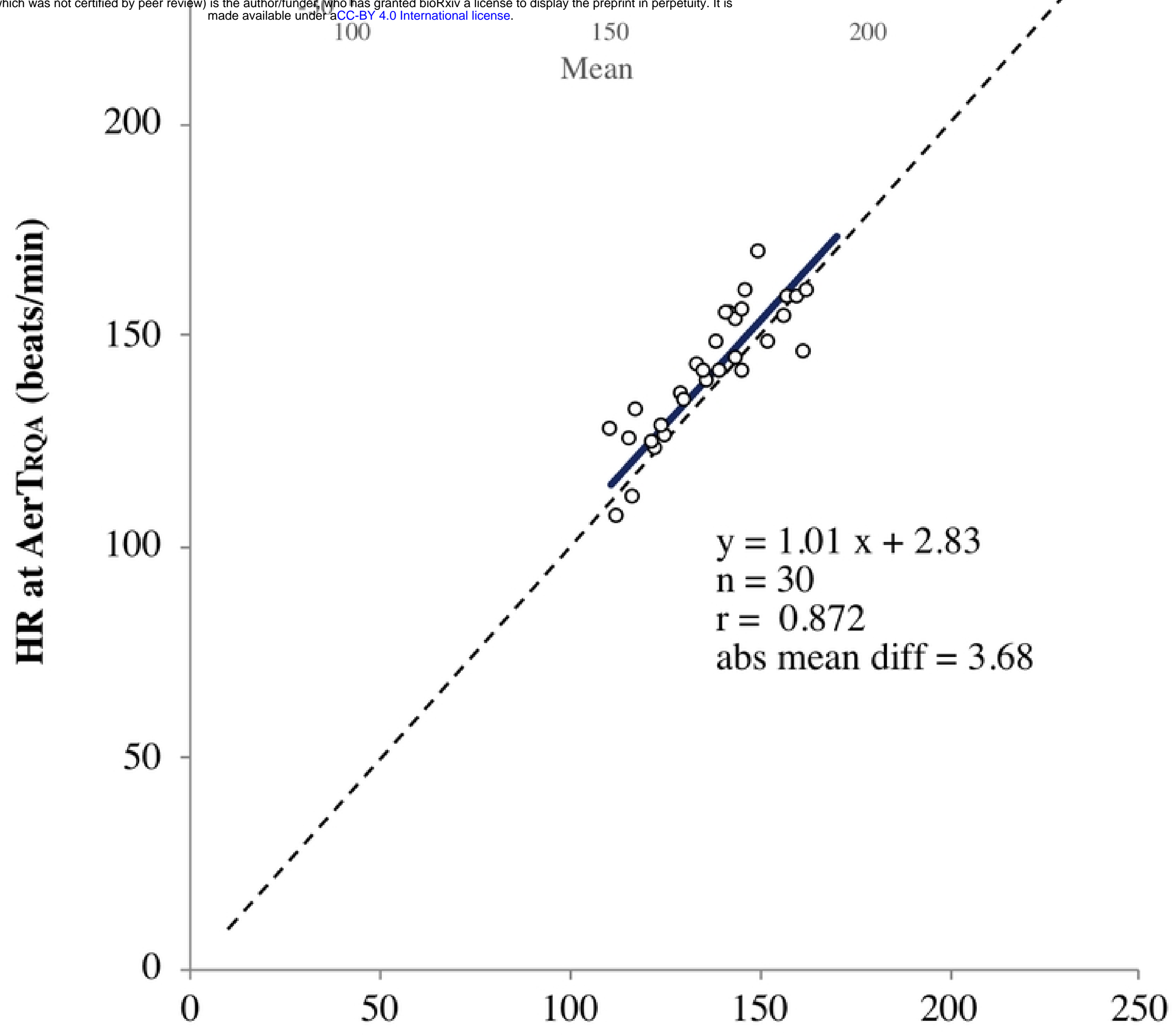

HR at AerTge (beats/min)

fig 2 a 


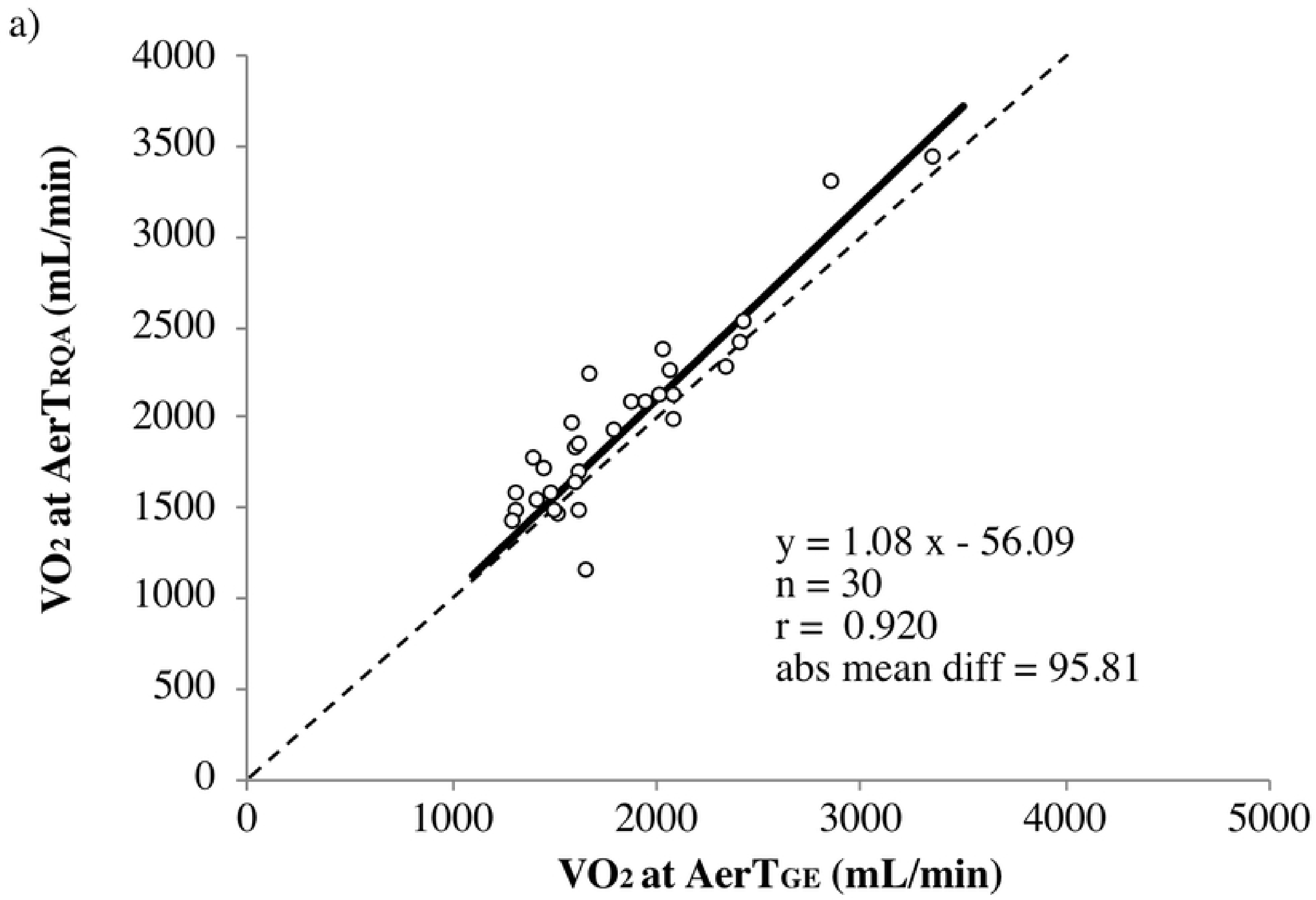

fig 3 a 


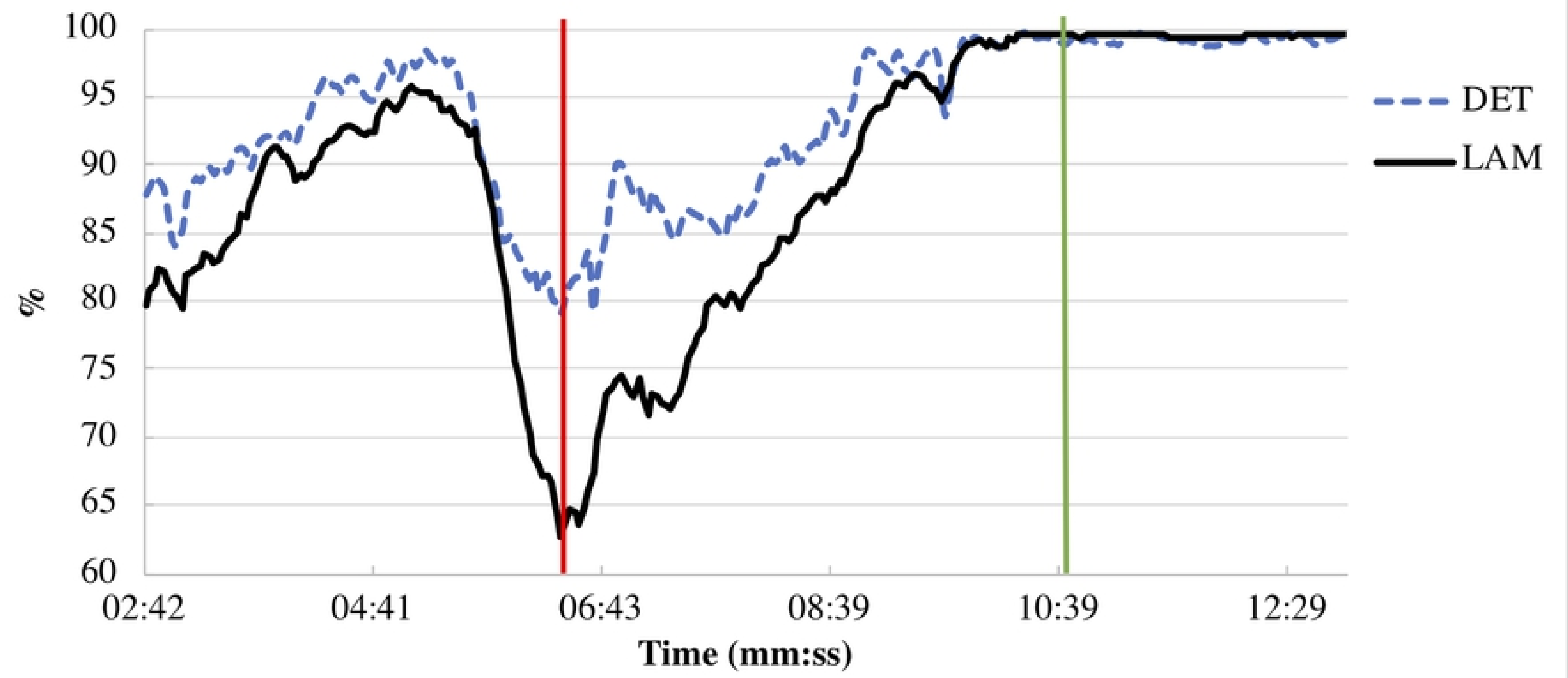

fig $1 \mathrm{~d}$ 
b)

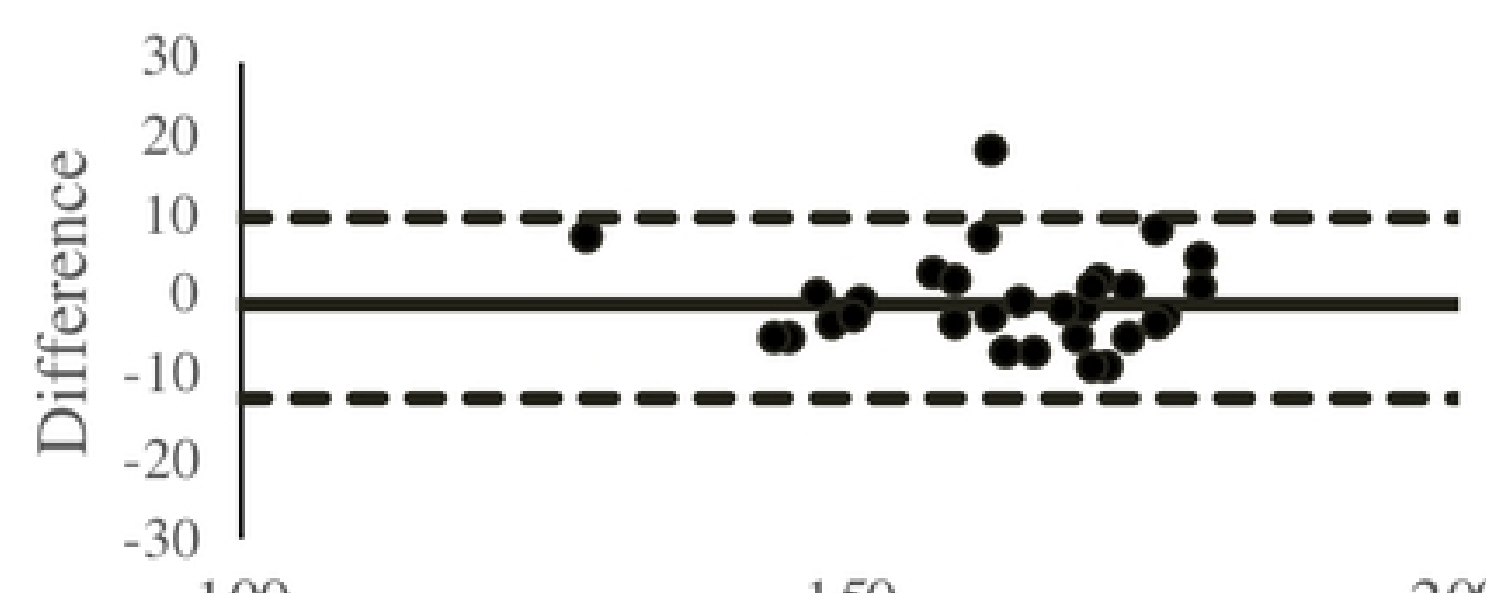

bioRxiv preprint doi: https://doi.org/10.1101/2021.03.22.436405; this version posted March 22, 2021. The copyright holder for this preprint (which was not certified by peer review) is the author/funder, who has granted bioRxiv a license to display the preprint in pêrpêtuity altis

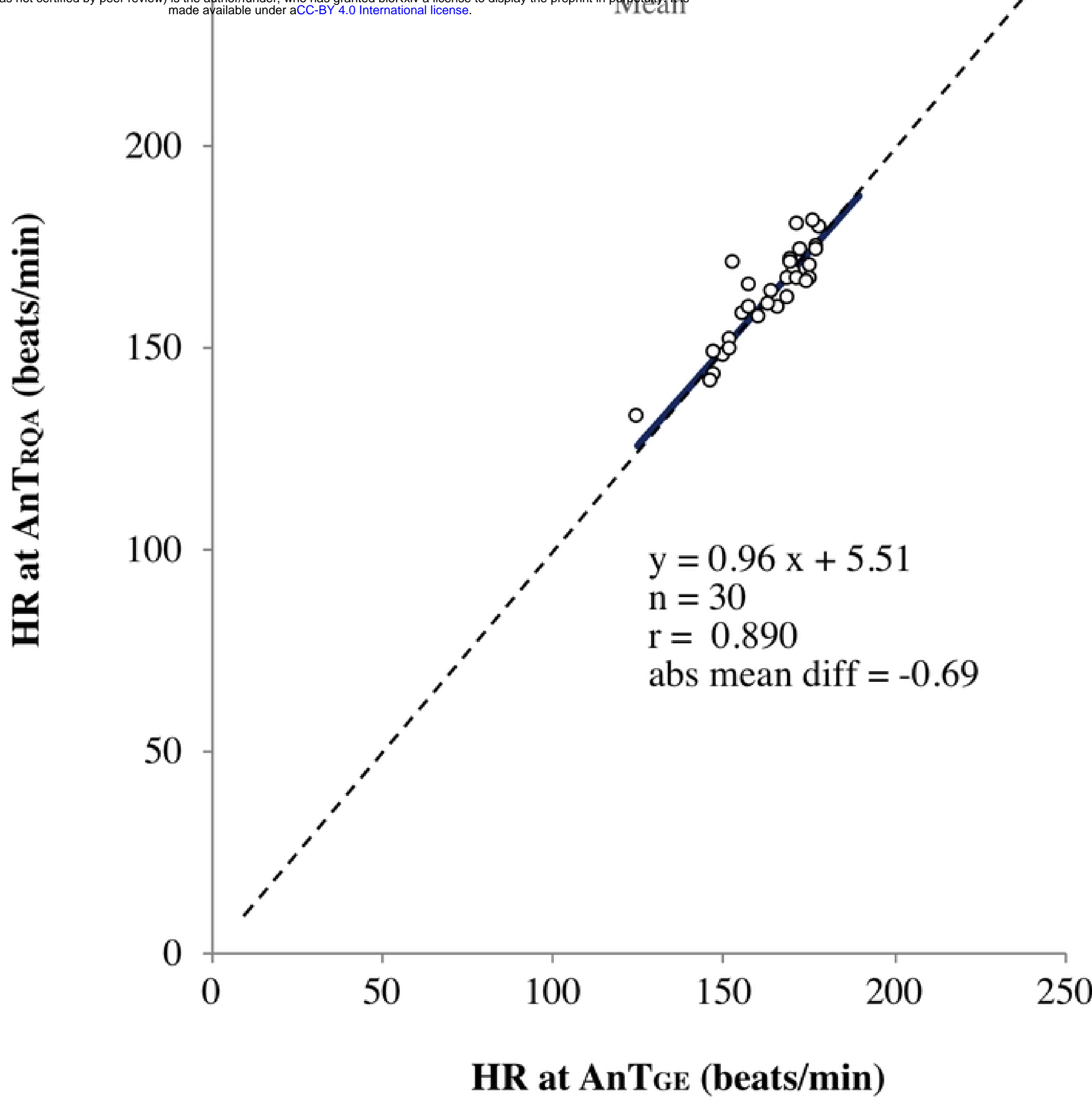

fig $2 \mathrm{~b}$ 
b)

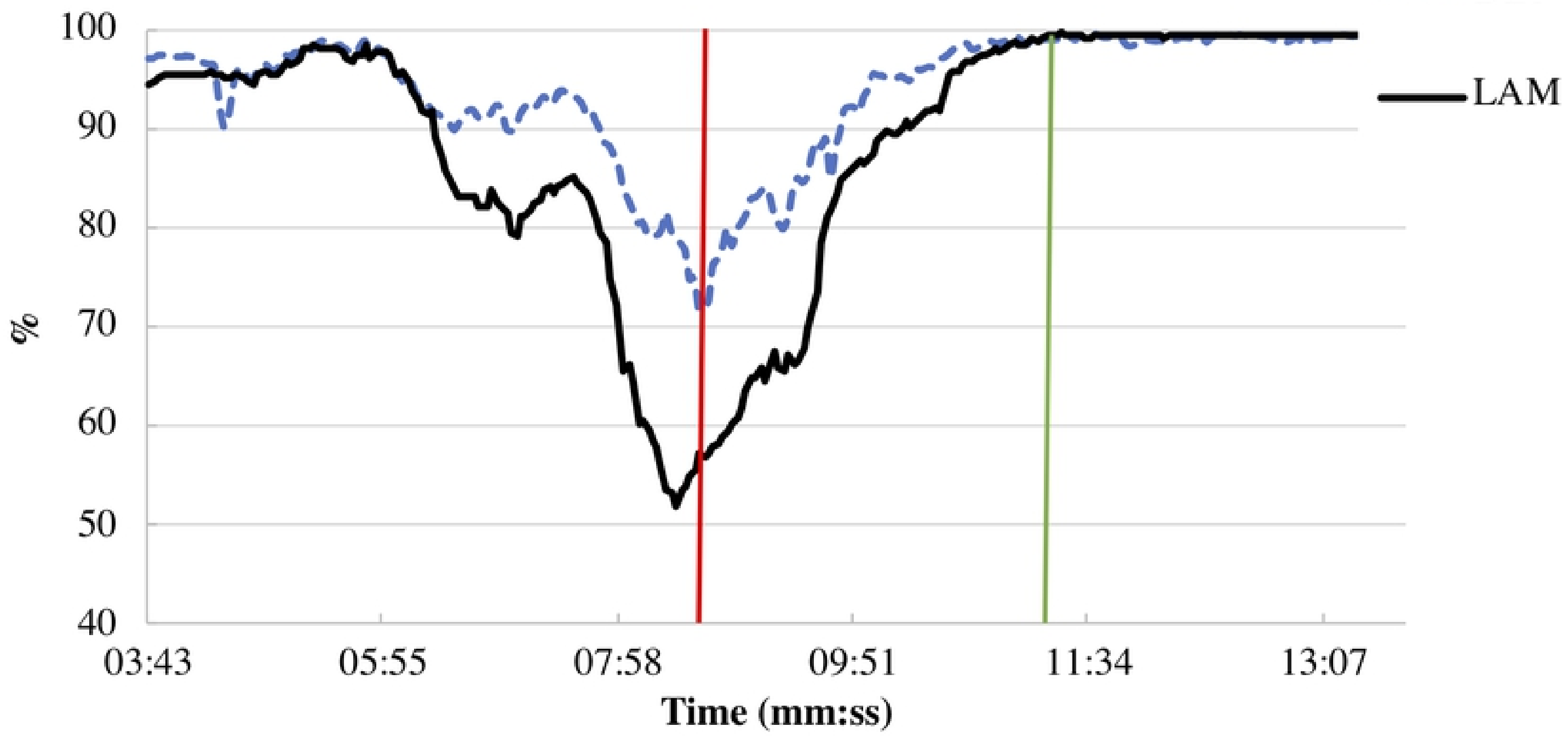

fig $1 \mathrm{~b}$ 
a)

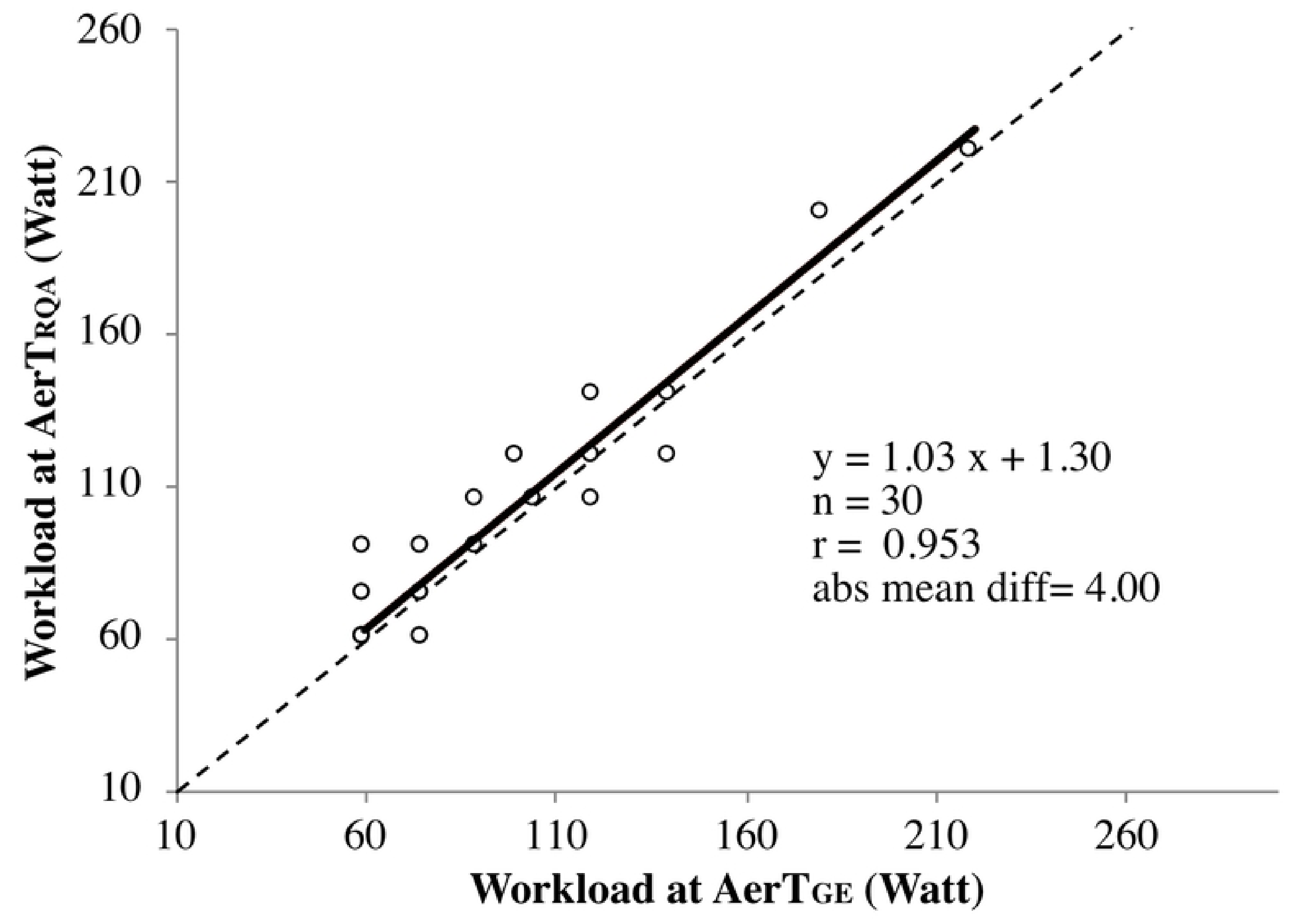

fig 4 a 
b)

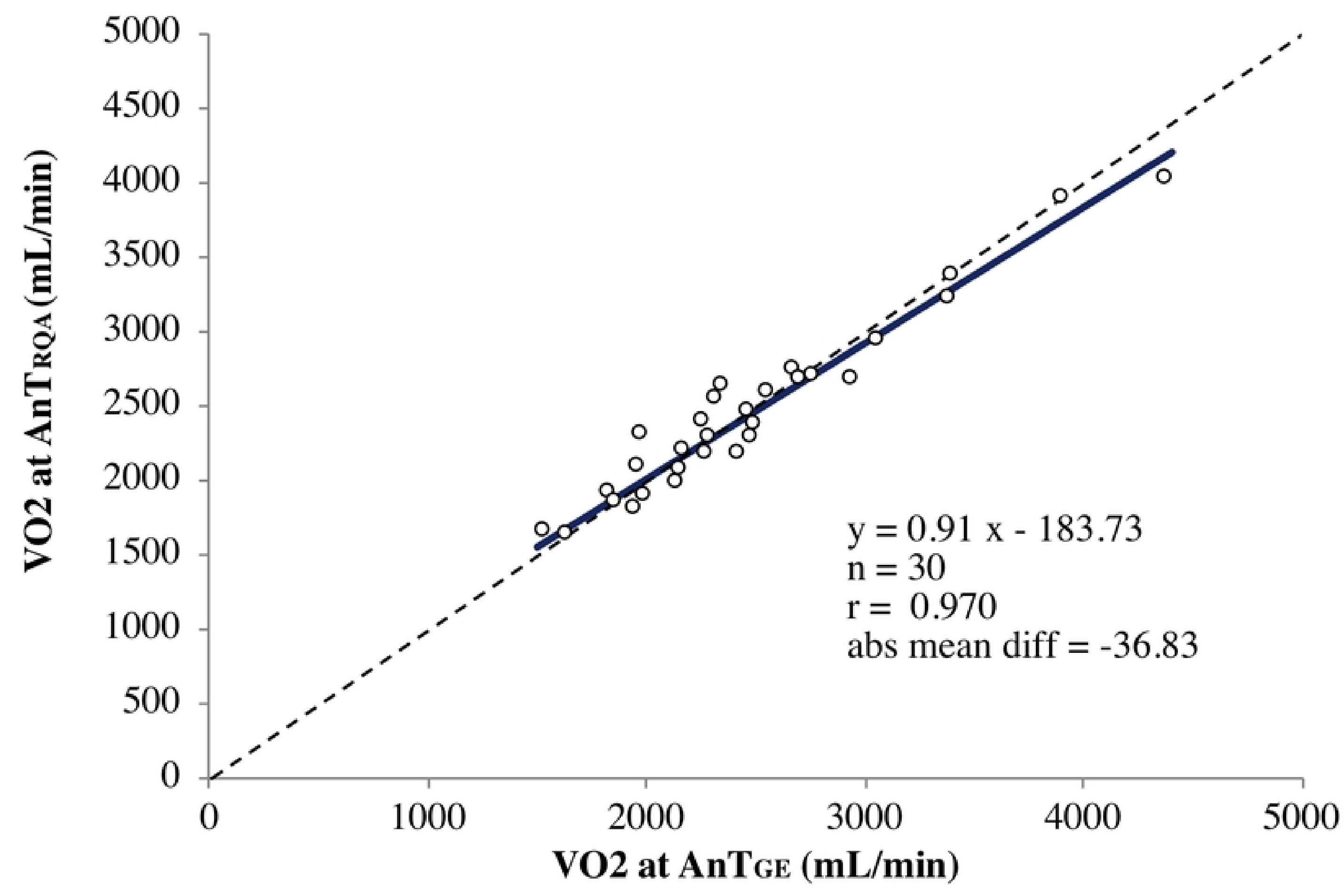

fig 3 b 
file=../dati $/$ lavi lade.txt

f inst $=59$

last $=421$

mean $=32.936$

randseq $=$ no

norm=Euclid

skip=0

delay $=1$

embed $=$ ?

resca le=meand ist meand ist $=100.000$ maxd ist $=294.595$

radius $=50$

colorbnd $=4$

line $=4$

matr $i x=363 * 363$

\#recur $=21703$

\# 1 ines $=772$

\%recur $=33.032 \%$ $\%$ determ $=98.678 \%$

$d_{\max }=361$

entropy $=5.395$

trend $=-63.723$

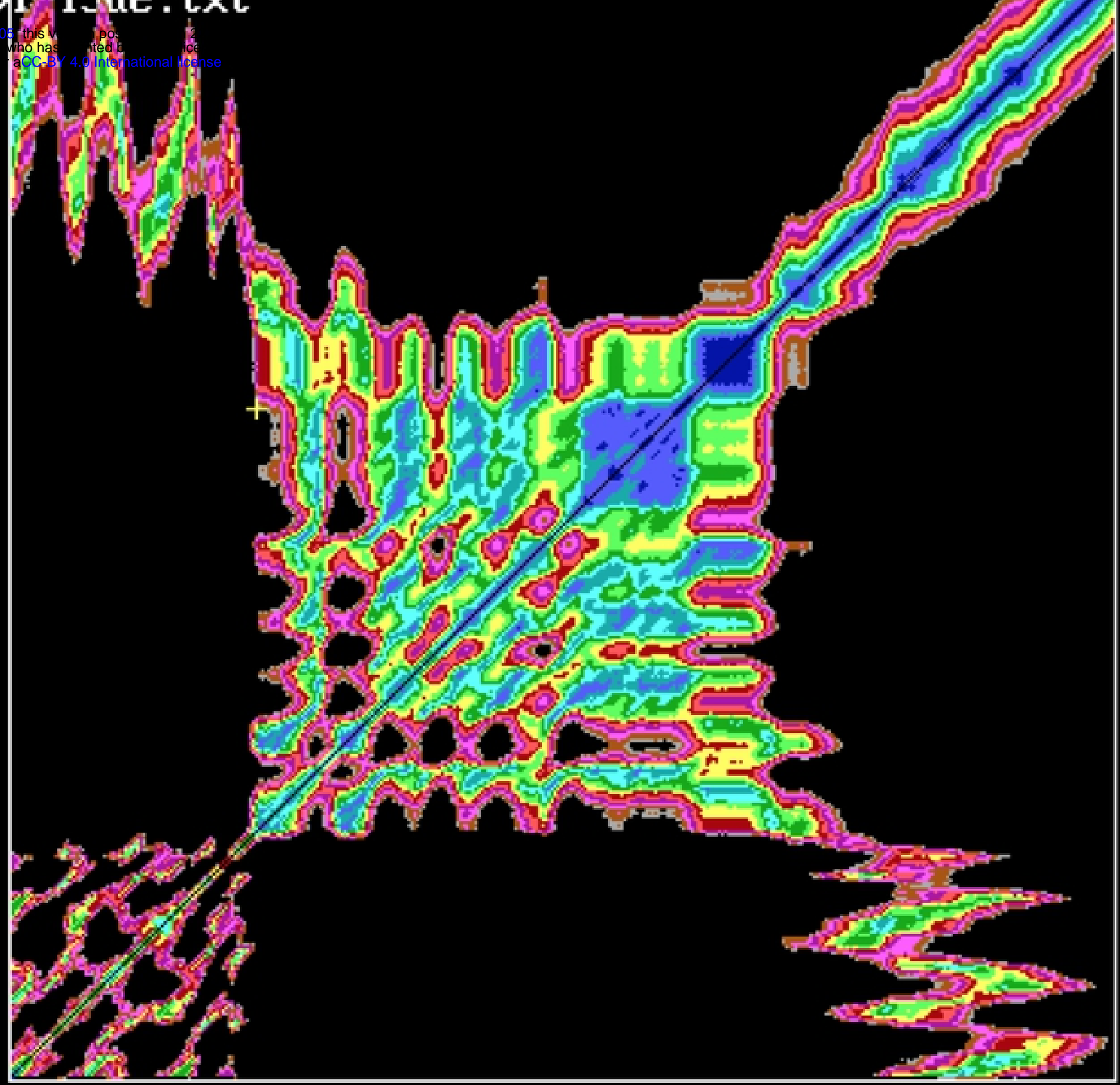

\%laminar $=99.244 \%$

$u \max =156$

trapt ime $=32.684$

$\operatorname{cur}(i, j)=140,279$

(
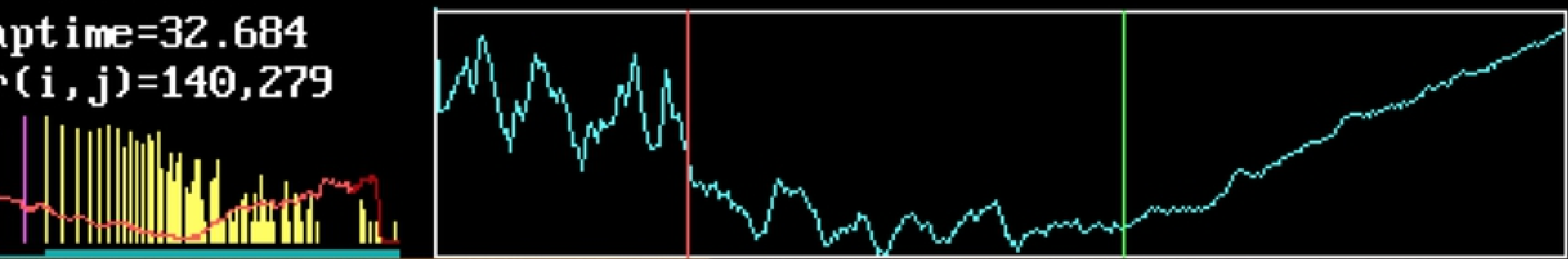

fig $1 \mathrm{c}$ 
file=../dati $/$ lavil/l1de.txt

f irst $=80$

last $=396$

mean $=11.690$

randseq $=$ no

norm=Eucl id

skip $=0$

delay $=1$

embed $=$ ?

resca le=meand ist meand ist $=100.000$ maxd ist $=359.235$

radius $=50$

colorbnd $=4$

line $=4$

matr $i x=317 * 317$

\#recur $=17524$

\# 1 ines $=395$

\%recur $=34.988 \%$

$\%$ determ=99.173\%

$d \max =303$

entropy $=5.757$

trend $=-256.504$

$\%$ laminar $=99.675 \%$

unax $=139$

trapt ime $=43.342$

$\operatorname{cur}(i, j)=188,277$

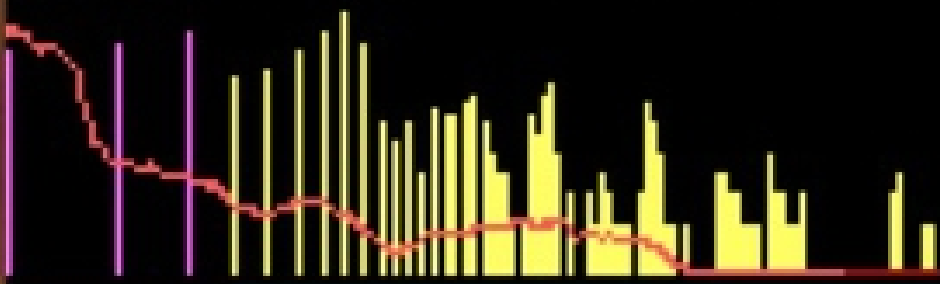

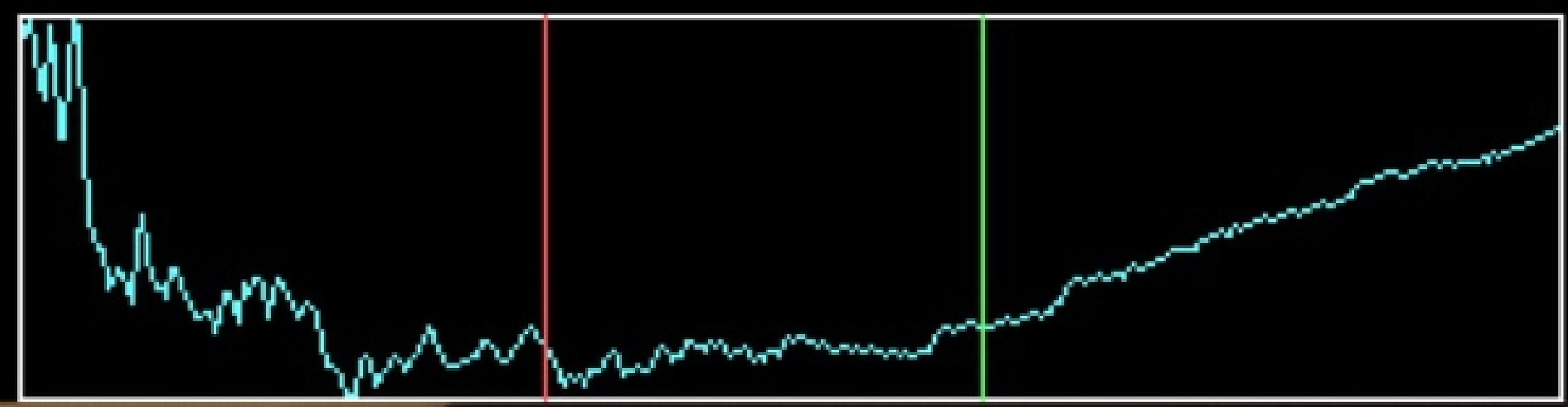

fig $1 \mathrm{a}$ 